\title{
Alterações reprodutivas, hematológicas e anatomopatológicas em fêmeas suínas com títulos de anticorpos contra Leptospira interrogans sorotipo icterohaemorrhagiae*
}

\section{Reproductive, haematologic and anatomapathological disorders in swine females with antibody titres to Leptospira interrogans serovar icterohaemorrhagiae}

\author{
Raul José Silva Girio, ${ }^{\star \star}$ Hilma Lúcia Tavares Dias, ${ }^{\star \star \star}$ Luis Antonio Mathias, ${ }^{\star \star}$ \\ Aureo Evangelista Santana, ${ }^{\star \star \star \star}$ Antonio Carlos Alessi ${ }^{\star \star \star \star \star}$
}

\begin{abstract}
Resumo
Foi realizada uma investigação em quatro rebanhos de suínos que apresentavam transtornos reprodutivos, com os objetivos de verificar a importância do sorotipo icterohaemorrhagiae como agente etiológico da leptospirose suína e identificar as alterações reprodutivas, hematológicas e anatomopatológicas provocadas pela infecção. De 158 fêmeas descartadas por apresentarem insuficiência reprodutiva e manifestações clínicas diversas, foram escolhidas 112, que reagiram contra Leptospira interrogans. Das 112 fêmeas reagentes, 106 apresentaram títulos contra o sorotipo icterohaemorrhagiae, cinco contra o sorotipo pomona e uma contra o sorotipo bratislava. Nas fêmeas com títulos de anticorpos contra o sorotipo icterohaemorrhagiae foram observadas alterações reprodutivas de abortamento, reabsorção embrionária, anestro, repetição irregular de cio, nascimento de crias fracas, natimorto, prolificidade $<5$ e descargas vulvares, além de alterações nos leucogramas e nos exames histopatológicos. Os leucogramas revelaram como mais importante alteração a leucocitose com neutrofilia e monocitose. Dos 106 suínos reagentes, 88 apresentaram alterações anatomopatológicas no aparelho geniturinário e 18 não apresentaram qualquer tipo de lesão. As principais lesões histopatológicas encontradas foram nefrite, nefrose, endometrite e salpingite.
\end{abstract}

Palavras-chave: Leptospirose; suínos; alterações reprodutivas.

\section{Introdução}

A leptospirose suína é considerada uma enfermidade economicamente importante, não só em decorrência de abortos e natimortos, mas também em função de elevadas taxas de letalidade que podem ser observadas em infecções septicêmicas pelo sorotipo icterohaemorrhagiae (Quinn et al., 1994). O sorotipo possui certa preferência por diversos hospedeiros vertebrados, dentre os quais se destacam os roedores sinantrópicos, principalmente o Rattus novergicus, que é considerado o seu maior disseminador (Faine, 1994).

Apesar do sorotipo pomona ser considerado o mais importante agente de problemas relacionados com a esfera reprodutiva de suínos (Kingscote, 1986), verifica-se, através da literatura, que nos últimos anos os sorotipos braiısuva e w.trohaemorrhagiae têm sido citados como grandes causadores de transtornos reprodutivos em fêmeas suínas (Bolin et al., 1991 ; Power, 1991 ; Van Til, Dohoo, 1991 ; Waal et al., 1991 ; Oliveira et al., 1994).

Com relação ao sorotipo icterohaemorrhagiae, alguns trabalhos relatam seu isolamento de suínos aparentemente sadios (Santa Rosa et al., 1962 ; McErlean, 1973), de suínos com problemas reprodutivos (Ellis et al., 1986) ou de suínos com insuficiência renal (Baker et al., 1988). No Brasil, a ocorrência do sorotipo icterohaemorrhagiae na espécie suína já foi constatada por meio de estudos sorológicos. Ávila et al. (1977), no estado de Minas Gerais, verificaram que $12,8 \%$ de amostras eram reagentes. Giorgi et al. (1981) examinaram soros de suínos de 11

\footnotetext{
* Trabalho premiado no XXIV Congresso Brasileiro de Medicina Veterinária - 3 a 7 de junho de 1996 - Goiânia, GO.

** Departamento de Medicina Veterinária Preventiva, Faculdade de Ciências Agrárias e Veterinárias, Unesp - Campus de Jaboticabal (FCAVJUnesp), Jaboticabal, SP CEP 14870-000.

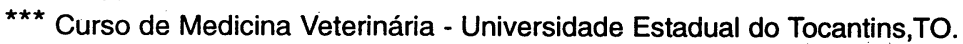

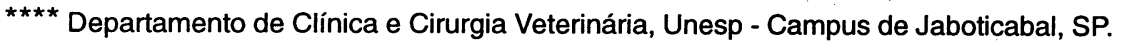

$\star \star \star \star \star$ Departamento de Patologia Veterinária, Unesp - Campus de Jaboticabal, SP.
} 
diferentes estados brasileiros e observaram que $2,4 \%$ foram reagentes. Girio et al. (1987), no estado de São Paulo, observaram, durante a fase aguda da leptospirose produzida pelo sorotipo icterohaemorrhagiae, abortamentos, natimortos e nascimento de crias fracas. Oliveira et al. (1994), no Rio Grande do Sul, incriminam esse sorotipo como responsável por problemas reprodutivos.

Devido a isso, o trabalho teve por objetivo verificar a importância do sorotipo icterohaemorrhagiae como agente etiológico da leptospirose suína e também identificar as alterações reprodutivas, hematológicas e anatomopatológicas provocadas pelo sorotipo em fêmeas suínas.

\section{Material e métodos}

\section{Rebanhos}

Foram estudadas quatro criações de suínos situadas na região norte do estado de São Paulo, constituindo uma população de 2.000 matrizes. Os animais eram criados confinados, sendo que periodicamente as fêmeas eram submetidas a exames sorológicos para o diagnóstico de brucelose, doença de Aujesky e parvovirose. A alimentação constituía-se de ração balanceada e de água de boa qualidade, e os animais eram periodicamente vacinados contra a peste suína clássica e febre aftosa. Todos os animais recebiam vermifugação periódica, e o manejo reprodutivo era feito por monta natural ou inseminação artificial.

\section{Histórico clínico}

As quatro criações foram escolhidas por apresentarem em seu rebanho alterações reprodutivas. De um total de 158 fêmeas descartadas por apresentarem alterações clínicas diversas, foram utilizadas 112 que apresentavam desempenho reprodutivo insuficiente e eram reagentes contra Leptospira interrogans na prova de soroaglutinação microscópica. As 46 fêmeas restantes não apresentaram qualquer problema reprodutivo e foram sorologicamente negativas.

\section{Exame clínico}

Nos 112 animais que apresentaram transtomos reprodutivos e foram reagentes contra antígenos de Leptospira interrogans, foram realizados exames clínicos gerais. Para isso, foram empregados métódos semiológicos veterinários indicados para o exame de cada sistema ou aparelho. O mesmo procedimento também foi adotado para as 46 fêmeas não reagentes.

\section{Colheita do material}

Com o intuito de complementar as informações obtidas no exame clínico, foram colhidas amostras de sangue para exames hematológicos e sorológicos das 158 fêmeas suínas.

\section{Resposta sorológica}

No soro sangüíneo de cada fêmea suína descartada, foram pesquisados anticorpos contra leptospiras, por meio da prova de soroaglutinação microscópica, segundo Santa Rosa (1970). Foram utilizados como antígenos os seguintes sorotipos de Leptospira interrogans: australis, bratislava, autumnalis, castellonis, bataviae, brasiliensis, butembo, canicola, whitcombi, grippotyphosa, icterohaemorrhagiae, javanica, panama, pomona, pyrogenes, hardjo, wolffi e shermani.

\section{Exames hematológicos}

Os exames hematológicos dos 158 suínos foram realizados logo após a colheita das amostras sangüíneas, obtidas com anticoagulante (EDTA solução 10\%). As contagens do número total de hemácias e de leucócitos foram realizadas por meio de contador automático da marca CELM, modelo CC510. A contagem diferencial de leucócitos foi efetuada por meio de esfregaços sangüíneos corados pelo Giemsa, conforme técnica descrita por Schalm et al. (1975).

\section{Exame anátomo-histopatológico}

Por ocasião do abate, os suínos foram inspecionados, e as alterações observadas foram anotadas em fichas próprias individuais. De cada fêmea, foi separado o aparelho urogenital para a realização de minuciosa avaliação macroscópica dos aspectos anatômico, biométrico, patológico e funcional. Fragmentos de todos os órgãos, tanto de áreas alteradas como de regiões aparentemente normais, foram colhidos de todos os animais e fixados em formalina neutra a $10 \%$. A seguir, o material foi processado segundo as técnicas histológicas de rotina, para obtenção de secções seriadas de aproximadamente cinco micrômetros de espessura. Os cortes foram corados com hematoxilina e eosina, para a investigação de eventuais alterações nos tecidos.

\section{Análise estatística}

Os resultados encontrados foram analisados por meio do teste de qui-quadrado.

\section{Resultados}

Os resultados da prova de soroaglutinação microscópica mostraram que 112 fêmeas descartadas reagiram contra Leptospira interrogans. Do total, 106 (94,6\%) reagiram contra o sorotipo icterohaemorrhagiae, cinco $(4,5 \%)$ contra o sorotipo pomona e uma $(0,9 \%)$ contra o sorotipo bratislava.

Das 158 fêmeas descartadas, 106 apresentaram transtornos reprodutivos diversos e foram reagentes contra o sorotipo icterohaemorrhagiae, conforme mostra a Tabela 1. Diante dos resultados obtidos, o teste de $\mathrm{X}^{2}$ acusou não haver di- 
Tabela 1: Número e percentagem de soros de suínos reagentes contra o sorotipo Icterohaemorrhagiae, reagentes contra outros sorotipos de Leptospira interrogans e não reagentes de acordo com a propriedade

ferença significativa, com $95 \%$ de probabilidade $\left(X^{2}=\right.$ 5,7847 , com três graus de liberdade), entre as quatro propriedades estudadas, no que diz respeito à ocorrência de fêmeas com problemas reprodutivos e reagentes contra 0 sorotipo icterohaemorrhagiae.

Na pesquisa foram observadas oito alterações reprodutivas. O abortamento foi a manifestação clínica mais freqüente $(23,6 \%)$, seguida por reabsorção embrionária $(21,7 \%)$, anestro $(15,1 \%)$, repetição irregular de cio $(13,2 \%)$, nascimento de crias fracas $(11,3 \%)$, natimorto $(8,5 \%)$, prolificidade menor que cinco crias por parto $(4,7 \%)$ e descargas vulvares $(1,9 \%)$ (Tabela 2$)$.
REAGENTES

\begin{tabular}{|c|c|c|c|c|c|c|c|c|}
\hline \multirow[t]{2}{*}{ Propriedade } & \multicolumn{2}{|c|}{ icterohaemorrhagiae } & \multicolumn{2}{|c|}{ Outros sorotipos } & \multicolumn{2}{|c|}{ Não-reagentes } & \multicolumn{2}{|c|}{ TOTAL } \\
\hline & $N^{\circ}$ & $\%$ & $N^{\circ}$ & $\%$ & $\mathrm{~N}^{\circ}$ & $\%$ & $\mathrm{~N}^{\circ}$ & $\%$ \\
\hline 1 & 34 & 68,0 & 3 & 6,0 & 13 & 26,0 & 50 & 100,0 \\
\hline 2 & 31 & 70,5 & 2 & 4,5 & 11 & 25,0 & 44 & 100,0 \\
\hline 3 & 28 & 66.7 & 1 & 2,4 & 13 & 30,9 & 42 & 100,0 \\
\hline 4 & 13 & 59,1 & 0 & 0 & 9 & 40,9 & 22 & 100,0 \\
\hline TOTAL & 106 & 67,1 & 6 & 3,8 & 46 & 29,1 & 158 & 100,0 \\
\hline
\end{tabular}

abortamento, e o menor, $1 / 100$, foi encontrado em dois animais que apresentavam anestro e repetição irregular de cio.

Os resultados da interpretação dos leucogramas das fêmeas que foram reagentes contra o sorotipo icterohaemorrhagiae mostraram que $36,8 \%$ apresentaram um aumento dos percentuais de leucócitos e monócitos e uma diminuição dos percentuais de neutrófilos. Verificou-se, ainda, que $19,8 \%$ dos suínos apresentaram leucocitose com neutrofilia e linfocitose e 9,4\% apresentaram leucopenia com linfocitopenia. Do total de amostras examinadas, $34,0 \%$ não apresentaram qualquer alteração no leucograma (Tabela 4).

Tabela 2: distribuição do número e porcentagem de fêmeas reagentes contra o sorotipo lchterohaemorrhagiae, de acordo com a propriedade e a alteração reprodutiva encontrada

\begin{tabular}{|c|c|c|c|c|c|c|c|c|c|c|c|c|c|c|c|c|c|c|}
\hline \multirow{3}{*}{ Propriedade } & \multicolumn{18}{|c|}{ Alteração Reprodutiva } \\
\hline & \multicolumn{2}{|c|}{$A B$} & \multicolumn{2}{|c|}{ AN } & \multicolumn{2}{|c|}{ DV } & \multicolumn{2}{|c|}{ NCF } & \multicolumn{2}{|c|}{ NM } & \multicolumn{2}{|c|}{ PB } & \multicolumn{2}{|c|}{ RE } & \multicolumn{2}{|c|}{ RIC } & \multicolumn{2}{|c|}{ TOTAL } \\
\hline & $\mathrm{N}^{\circ}$ & $\%$ & $\mathrm{~N}^{\circ}$ & $\%$ & $\mathrm{~N}^{0}$ & $\%$ & $\mathrm{~N}^{\circ}$ & $\%$ & $\mathrm{~N}^{\circ}$ & $\%$ & $\mathrm{~N}^{\circ}$ & $\%$ & $-\mathrm{N}^{\circ}$ & $\%$ & $\mathrm{~N}^{\circ}$ & $\%$ & $\mathrm{~N}^{0}$ & $\%$ \\
\hline 1 & 08 & 23,5 & 08 & 23,5 & - & - & 03 & 8,8 & 05 & 14,7 & 01 & 2,9 & 04 & 11,8 & 05 & 14,7 & 34 & 100,0 \\
\hline 2 & 04 & 12,9 & 06 & 19,4 & 01 & 3,2 & 05 & 16,1 & 03 & 9,7 & 03 & 9,7 & 05 & 16,1 & 04 & 12,9 & 31 & 100,0 \\
\hline 3 & 10 & 35,7 & 01 & 3,6 & 01 & 3,6 & 03 & 10,7 & - & - & 01 & 3,6 & 08 & 28,6 & 04 & 14,3 & 28 & 100,0 \\
\hline 4 & 03 & 23.1 & 01 & 7,7 & - & - & 01 & 7,7 & 01 & 7,7 & - & - & 06 & 46,2 & 01 & 7,7 & 13 & 100,0 \\
\hline TOTAL & 25 & 23,6 & 16 & 15,1 & 02 & 1,9 & 12 & 13,4 & 09 & 8,5 & 05 & 4,7 & 23 & 21,7 & 14 & 13,2 & 106 & 100,0 \\
\hline $\begin{array}{l}B=\text { Prolificidad } \\
V=\text { Descarga }\end{array}$ & are & & & $\begin{array}{l}\mathrm{NM}= \\
\mathrm{AN}= \\
\mathrm{RIC}=\end{array}$ & Rep & ção & & do cio & & & $=$ & $i^{3}$ & to $\mathrm{d}$ & crias & acas & & & \\
\hline
\end{tabular}

Os títulos sorológicos encontrados nas 106 fêmeas reagentes contra o sorotipo icterohaemorrhagiae variaram entre 1/100 e $1 / 25.600$ (Tabela 3). O título mais freqüentemente encontrado foi 1/800, observado em 31 animais. O maior título, 1/ 25.600, foi verificado em uma fêmea que apresentou
Os exames anatomo-histopatológicos no aparelho urinário das fêmeas suínas reagentes contra o sorotipo icterohaemomagiae revelaramnefrite em 12 animais, nefrose e cistite em 10 animais, nefrite, nefrose e cistite em dois animais ecistos renais em um animal. No aparelho reprodutor,
Tabela 3: Número de fêmeas suínas, de acordo com as manifestações reprodutivas e como título de anticorpos contra o sorotipo icterohaemorrhagiae

\begin{tabular}{lcccccccccccc}
\hline & \multicolumn{1}{c}{} & \multicolumn{1}{c}{ TíTULO } & & \multicolumn{1}{c}{$\begin{array}{c}\text { Total } \\
\text { fêmeas }\end{array}$} \\
\cline { 2 - 12 } Alteração reprodutiva & $1 / 100$ & $1 / 200$ & $1 / 400$ & $1 / 800$ & $1 / 600$ & $1 / 3200$ & $1 / 6400$ & $1 / 12800$ & $1 / 25600$ \\
\hline Abortamento & - & - & 02 & 03 & 08 & 08 & 02 & 01 & 01 & 25 \\
Anestro & 01 & 02 & 02 & 06 & 04 & - & 01 & - & - & 16 \\
Descargas vulvares & - & - & 01 & - & 01 & - & - & - & - & 02 \\
Nasc. Crias fracas & - & - & - & 08 & 02 & 01 & 01 & - & - & 12 \\
Natimorto & - & 01 & 01 & 02 & 04 & 01 & - & - & - & 09 \\
Prolificidade (<5) & - & - & 03 & - & - & 01 & 01 & - & - & 05 \\
Reabsorção embrionária & - & 02 & 03 & 04 & 06 & 06 & 01 & 01 & - & 23 \\
Repetição irregular do cio & 01 & - & - & 08 & 02 & 01 & 02 & - & - & 14 \\
\hline TOTAL & 02 & 05 & 12 & 31 & 27 & 18 & 08 & 02 & 01 & 106 \\
\hline
\end{tabular}


Tabela 4: Resultados da interpretação dos leucogramas de fêmeas suínas, de acordo com o número e a porcentagem de reagentes contra o sorotipo icterohaemorrhagiae

\begin{tabular}{lrr}
\hline \multirow{2}{*}{ Achados } & \multicolumn{2}{c}{ Reagentes } \\
\cline { 2 - 3 } & № & $\%$ \\
\hline Leucocitose com neutrofilia e monocitose & 39 & 36,8 \\
Luecocitose com neutrofilia e linfocitose & 21 & 19,8 \\
Leucopenia com linfocitopenia & 10 & 9,4 \\
Normal & 36 & 34,0 \\
\hline Total & 106 & 100,0 \\
\hline
\end{tabular}

observaram-se alterações em 53 animais, sendo que endometrite e salpingite foram verificadas em $24(22,7 \%)$ animais, vaginite em $15(14,2 \%)$ animais e endometrite em 14 $(13,2 \%)$ animais. Das 106 fêmeas reagentes, $18(17,0 \%)$ não apresentaram qualquer tipo de alteração, tanto no aparelho urinário como no reprodutor (Tabela 5).

Tabela 5: Distribuição do número e porcentagem de reagentes contra o sorotipo icterohaemorrhagiae, de acordo com os tipos de alterações anátomo-histopatológicas do aparelho urinário e genital de fêmeas suínas

\begin{tabular}{lrr}
\hline \multirow{2}{*}{ Achados } & \multicolumn{2}{c}{ Reagentes } \\
\cline { 2 - 3 } & № & $\%$ \\
\hline Cistite & 10 & 9,4 \\
Nefrite & 12 & 11,3 \\
Nefrose & 10 & 9,4 \\
Nefrite, Nefrosee Cistite & 02 & 1,9 \\
Cistos Renais & 01 & 0,9 \\
Endometrite & 14 & 13,2 \\
Endometrite e Salpingite & 24 & 22,7 \\
Vaginite & 15 & 14,2 \\
Normal & 18 & 17,0 \\
\hline Total & 106 & 100,0 \\
\hline
\end{tabular}

\section{Discussão}

A grande maioria dos suínos descartados, devido ao inadequado desempenho reprodutivo, apresentou aglutininas contra Leptospira interrogans. De acordo com Faine (1994), os casos de leptospirose suína são marcados por prejuízos econômicos devido às várias alterações reprodutivas que podem ocorrer no rebanho suíno. Dentre os inúmeros sorotipos de $L$. interrogans com ampla distribuição mundi- al, o sorotipo pomona sempre teve uma grande participação nos casos de leptospirose na espécie suína, principalmente naqueles relacionados com abortamentos, natimorto e nascimentos de crias fracas (Kingscote, 1986 ; Van Til, Dohoo, 1991).

O sorotipo icterohaemorrhagiae foi o de maior ocorrência $(67,1 \%)$ nos casos relacionados com transtornos reprodutivos. Quinn et al. (1994) também mencionam o envolvimento do sorotipo icterohaemorrhagiae em casos de infertilidade, abortamento e natimorto, além de ser incriminado por altas taxas de mortalidade em suínos jovens. A importância desse sorotipo parece estar mais re- lacionada com alta infestação de roedores nas criações (Girio et al., 1987 ; Faine, 1994).

Em contrapartida, Power (1991) e Oliveira et al. (1994) relataram que a infecção mista produzida pelos sorotipos icterohaemorrhagiae e bratislava pode causar reabsorção embrionária em fêmeas suínas. No presente trabalho, essa alteração foi verificada em $21,7 \%$ dos animais reagentes somente contra o sorotipo icterohaemorrhagiae. Entretanto, vale ressaltar que podem ocorrer reações sorológicas cruzadas entre esses dois sorotipos, tal como observaram Bolin et al. (1991).

As alterações como descargas vulvares e anestro são citadas por Waal et al. (1991), em casos de suínos reagentes contra o sorotipo bratislava, mas tais alterações foram encontradas em fêmeas reagentes contra o sorotipo icterohaemorrhagiae. Para melhor caracterizar as infecções do aparelho reprodutor, seria importante a realização de culturas bacteriológicas e a identificação dos agentes isolados, o que não foi feito no estudo, uma vez que a pesquisa visou exclusivamente estudar o histórico reprodutivo em animais reagentes contra $L$. interrogans.

A prova de soroaglutinação microscópica revelou títulos de aglutininas entre $1 / 100$ e 1/25.600 contra o sorotipo icterohaemorrhagiae. Os títulos de 1/12.800 e 1/25.600 foram encontrados em fêmeas que haviam abortado recentemente, caracterizando com isso uma possível fase aguda de infecção. Casos de abortamentos em suínos que apresentaram títulos sorológicos de $1 / 400$ contra o sorotipo bratislava foram verificados por Ellis et al. (1986). Observação parecida foi realizada no presente estudo, com o sorotipo icterohaemorrhagiae. Títulos de aglutininas baixos podem indicar início de infecção como também uma infecção crônica de leptospirose. A grande maioria dos títulos sorológicos encontrados variou entre 1/100 e 1/6.400. Giorgi et al. (1981) obtiveram resultados similares em rebanhos de suínos reagentes contra o sorotipo icterohaemorrhagiae e que apresentavam alterações reprodutivas diversas. Em contrapartida, verificou-se no estudo que 46 animais apresentaram insuficiência reprodutiva e não foram reagentes contra nenhum sorotipo de $L$. interrogans.

A leucocitose por neutrofilia e monocitose foi verificada em $39(36,8 \%)$ suínos com transtornos reprodutivos. Tal quadro leucocitário geralmente é indicativo de infecção generalizada, processo tóxico ou ainda de distúrbios metabólicos, como alteração renal. A monocitose observada poderia estar relacionada com a existência de um processo infeccioso de evolução aguda, o que poderia diferenciar o quadro de alteração renal de leptospirose das outras formas não infecciosas de nefropatias (Schalm et al., 1975). Outra alteração hematológica observada, leucopenia por linfocitopenia, poderia estar relacionada com estresse, possivelmente causado pelo manejo dos animais.

Os achados patológicos de nefrite constituíram uma importante lesão, que pode ser causada por vários sorotipos patogênicos de leptospiras. Essa alteração foi descrita por Baker et al. (1988) em suínos reagentes contra o 
sorotipo icterohaemorrhagiae. A cistite não é mencionada como uma alteração importante, mas a nefrose pode estar relacionada com casos agudos de leptospirose. No apareIho genital, as endometrites, salpingites e vaginites foram as alterações mais freqüentes observadas nas fêmeas reagentes contra o sorotipo icterohaemorrhagiae. Essas inflamações teciduais não são comumente descritas em casos de leptospirose, mas possivelmente poderiam ser importantes devido à facilidade de disseminação das leptospiras no aparelho reprodutor, principalmente de fêmeas. Entretanto, as salpingites produzidas pelo sorotipo bratislava poderiam desencadear um processo de infecção uterina (Power, 1991). Deve-se considerar, no entanto, que $17,0 \%$ das fêmeas reagentes para o sorotipo icterohaemorrhagiae não apresentaram qualquer alteração anátomo-histopatológicas no aparelho geniturinário, somente apresentando problemas reprodutivos. Essa localização do sorotipo icterohaemorrhagiae no aparelho geniturinário sem causar lesões pode estar associada à condição de portador renal, conforme verificaram Santa Rosa et al. (1962), McErlean (1973) e Ávila et al. (1977), em animais sem qualquer alteração clínica de leptospirose.

\begin{abstract}
A study, involving four pig herds showing reproductive disorders, was carried out in order to verify the importance of serovar icterohaemormagiae as aetiologic agent of swine leptospirosis and to identify the reproductive, haematologic and anatomopathological alterations caused by this serovar. One hundred and fifty-eight sows, discarded due to reproductive insufficiency and several clinical manifestation, were examined for antibody titres to Leptospira interrogans, by the microscopic agglutination test, using as antigens serovars representatives of 18 serogroups. From those 158 sows, 112 with antibody titres to Leptospira interroganswere chosen. Besides the serological tests, the sows were also submitted to clinical examination and blood samples were taken for haematologic tests. From these 112 sows, 106 had antibody titres to the serovar icterohaemorrhagiae, 5 to the serovar pomona and one had antibody titre to the serovar bratislava. Among the 106 sows with antibody titres to serovar icterohaemorrhagiae, eight different kinds of reproductive disorders were observed, and the most frequent was the abortion, observed in $23.5 \%$ of those animals. The leucograms of the sows reacting to serovar icterohaemornagiae showed as the most important alterations leukocytosis with neutrophilia and monocytosis. Histopathologic examinations of geniturinary organs were performed through routine histologic techniques and sections were stained with hematoxylin and eosin (HE). From the 106 sows reacting to serovar icterohaemormagiae, 88 showed anatomopathologic disorders in the geniturinary system, and 18 showed no lesion. The most frequent lesions were nephritis, nephrosis, endometritis and salpingitis.
\end{abstract}

Keywords: Leptospirosis; sows; reproductive disorders.

\section{Referências bibliográficas}

ÁVILA, F.A., MOREIRA, E.C., VIANA, F.C. et al. Freqüência de aglutininas antileptospiras em soros de suínos de Minas Gerais. Arq. Esc. Vet. UFMG, v. 29, n. 3, p. 263-268, 1977.

BAKER, T.F., McEWEN, S.A., PRESCOTT, J.F. et al. The prevalence of leptospirosis and its association with multifocal interstitial nephritis in swine at slaughter. Acta. Vet. Scand., v. 84, p.306-308, 1988.

BOLIN, C.A., CASELLS, J.A., HILL, H.T. et al. Reprodutive failure associated with Leptospira interrogans serovar bratislava infection of swine. J. Vet. Diag. Inv., v.3, n. 2, p.152-154, 1991.

ELLIS, W.A., McPARLAND, P.J., BRYSON, D.G. et al. Prevalence of Leptospira infection in aborted pigs in Northern Ireland. Vet. Rec., v. 118, n. 3, p. 63-65, 1986.

FAINE, S. Leptospira and leptospirosis. Boca Raton : CRC Press, 1994.

GIORGI, W., TERUYA, J. M., SILVA, A. S. et al. Leptospirose: resultados das soroaglutinações realizadas no Instituto Biológico de São Paulo, durante os anos de 1974/1981. Biológico, São Paulo, v. 47, n. 11, p. 299-309, 1981.

GIRIO, R.J.S., MATHIAS, L.A., CASTANIA, V.A. et al. Ocorrência de surtos de leptospirose suína e humana em três propriedades do município de Viradouro-SP. Ciência Vet. Jaboticabal, v. 1, n. 2, p. 24-25, 1987.

KINGSCOTE, B.F. Leptospirosis outbreak in a piggery in southern Alberta. Can. Vet. J., v. 27, n. 4, p. 188-190, 1986.
MCERLEAN, B.A. The isolation of leptospirae from the kidneys of bacon pigs. Irish Vet. J., v. 27, p. 185-186, 1973.

OLIVEIRA, S.J., BOROWSKI, S.M., BARCELLOS, D.E.S.N. Evidência de infecção por Leptospira bratislava em transtornos reprodutivos em suínos. Ciência Rural, v. 24, n. 2, p. 345-348, 1994.

POWER, S.B. Diagnosing leptospira in pigs. Vet. Rec., v. 128, n. 2, p. 43, 1991.

QUINN, P. J., CARTER, M. E., MARKEY, B. et al. Clinical Veterinary Microbiology. London : Wolfe Publishing, 1994.

SANTA ROSA, C.A. Diagnóstico laboratorial das leptospiroses. Rev. Microbiol., v. 1, p. 97-109, 1970.

SANTA ROSA, C.A., CASTRO, A.F.P., CALDAS, A.D. Isolamento de Leptospira icterohaemorrhagiae e Leptospira hyos de suínos abatidos em matadouro. Arq. Inst. Biol., São Paulo, v. 20, p. 285-292, 1962.

SCHALM, O. W., JAIN, N. C., CARROL, E. J. Veterinary Hematology. 3. ed. Philadelphia : Lea \& Febiger, 1975.

VAN TIL, L.D., DOHOO, I.R. A serological survey of leptospirosis in Prince Edward Island swine herds and its association with infertility. Can. J. Vet. Res., v. 55, p. 352-355, 1991.

WAAL, C.A.H., HARTMANN, E.G., BOKHOUT, B.A. et al. Porcine leptospirosis: serological diagnosis of infection with Leptospira interrogans serotype bratislava. Tij. Dier., v. 116, n. 4, p. 173-179, 1991. 